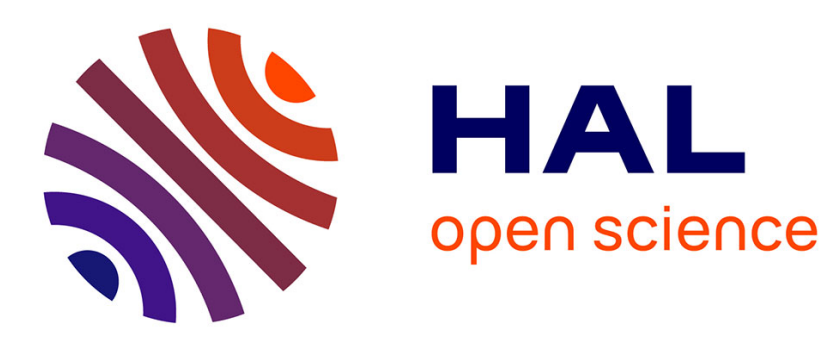

\title{
Liberalisation of the electricity sector and development of distributed generation: Germany, United Kingdom and France
}

Philippe Menanteau

\section{- To cite this version:}

Philippe Menanteau. Liberalisation of the electricity sector and development of distributed generation: Germany, United Kingdom and France. Energy and Environment, 2004, 15 (2), pp.239-248. halshs00103299

\section{HAL Id: halshs-00103299 \\ https://shs.hal.science/halshs-00103299}

Submitted on 30 Sep 2014

HAL is a multi-disciplinary open access archive for the deposit and dissemination of scientific research documents, whether they are published or not. The documents may come from teaching and research institutions in France or abroad, or from public or private research centers.
L'archive ouverte pluridisciplinaire $\mathbf{H A L}$, est destinée au dépôt et à la diffusion de documents scientifiques de niveau recherche, publiés ou non, émanant des établissements d'enseignement et de recherche français ou étrangers, des laboratoires publics ou privés. 


\section{Liberalisation of the electricity sector and development of distrib- uted generation: Germany, United Kingdom and France.}

Philippe Menanteau, Departement Energie et Politiques de l'Environnement, LEPII, Grenoble University and CNRS, France

\section{Introduction: the stakes involved in the devel- opment of distributed generation}

Historically, electricity systems have been made up of small local networks gradually becoming incorporated to benefit from the diversity of demand and the economies of scale in electricity generation that are possible with large interconnected systems. Today, this logic would seem to have certain limits, now that the benefits related to the size of production units appear to have been exhausted and in view of the growing difficulties in developing new transmission infrastructures. At the same time, there have been considerable improvements in the technical and economic performance of modular generating techniques, which are now enjoying significant development under the effect of electricity sector liberalisation and policies to reduce greenhouse gas emissions.

The aim of the present paper is to analyse the effect of electricity sector liberalisation on the development of distributed generation, and more specifically to examine the conditions in which these new electricity generating technologies can be diffused in a liberalised framework. The paper looks first at how competition has affected the electricity market. This analysis is followed by an examination of the problems of integrating distributed generation into electricity systems. In the third part of the paper, three brief case studies highlight the principal differences between Germany, the United Kingdom and France in the field of distributed generation. This brief analysis reveals that the institutional framework in which distributed generation must operate and the price signals given to electricity sector actors play as big a part as traditional incentives, certificates, bidding systems or guaranteed feed-in tariffs in driving the deployment process.

\section{The impact of electricity sector liberalisation on distributed generation}

As a result of liberalisation, increased competition and the segmentation of activities (generation, transmission, distribution, sales) is changing the strategies of operators who were previously in a monopoly position and is forcing them to respond to the arrival of new market entrants. With the opening up of electricity markets, the introduction of competition among producers, the freedom of consumers to change their supplier, and the development of transparent, nondiscriminatory grid access rules are encouraging new entrants to the sector and the appearance of new products and services that can take advantage of the par- ticular benefits of distributed generation (see also Markard et al., 2003).

A consequence of market liberalisation is the transformation of the environment in which electricity companies operate and in which they now have to compete. In a liberalised market, investment decisions are made in a context of much higher risk than before: greater price volatility on the electricity markets, uncertainty surrounding the stability of the regulatory context (market rules, environment legislation, etc.) and changes in demand. As a consequence, producers tend to set aside projects with long payoff periods, which are more open to risk, in favour of more flexible, less capital-intensive projects that bring rapid returns (Esnault, 2002).

Electricity sector liberalisation also means, at least in theory, more transparent tariffs that supposedly better reflect real costs, both for generation as well as transmission and distribution. Greater transparency of tariffs could mean time- or geographically differentiated tariffs. These cost differences can become more apparent with market liberalisation and act as an incentive to set up distributed generating units (in low density rural areas for ex.).

Finally, and most important, liberalisation changes the relationship between suppliers and customers. Competing companies generally try to find ways of differentiating themselves from others in the market. This is especially true of new suppliers entering the market who are not necessarily able to compete immediately with the large companies on energy prices alone. Diversification strategies focus on products, with the sale of $\mathrm{kWh}$ from renewable energy sources (green electricity), for example, or on services with multi-energy services or general management of energy services, which might include on-site generation and equipment maintenance, energy efficiency improvement measures (audits, for example) or service quality and reliability improvements.

On the other hand, it would be wrong to ignore the possible negative effects of these same developments on energy efficiency programmes and the promotion of new energy technologies, without which the development prospects for distributed generation would be far less promising. Thus, as former monopolists see their incomes eroding, they abandon demand-side management measures or their interest in renewables if there is no financial reward. Similarly, the ban on crosssubsidisation means that it is no longer possible to recover the additional costs associated with certain measures from all electricity consumers across the board. Incentives to invest in distributed generation as a way of avoiding investment in infrastructure reinforcement, which existed in a vertically-integrated monopoly situation, can disappear once the different parts are separated. Finally, the reluctance of electricity companies to take risks in an increasingly uncertain environment may act to the detriment of renewable energy sources which are characterised by unfavourable price structures.

In general, electricity market liberalisation creates opportunities for distributed generation by encouraging 
ENER Forum 5. Technological change, market reform and climate policies. Bucharest, Romania, 16-17 October 2003 - Presented papers DRAFT 19-10-03

new producers to enter the market and electricity companies to diversify into new market niches or new services. But the introduction of competition, unbundling and the declining influence of the States also have an opposite effect on measures to promote energy efficiency or the development of cogeneration and renewable energy. To support the development of these particular technologies and enlarge the opportunities opened by liberalisation, appropriate incentive schemes must be created in order to overcome the constraints of integrating distributed generation into the electricity grid.

\section{Key issues for the development of distributed generation}

Although liberalisation creates conditions which are generally more favourable to the development of certain categories of distributed generation, there are still significant constraints limiting such development. Essentially, they are a result of the technological trajectory adopted to create the electricity infrastructures and of the related incentive schemes that favour the development of centralised production systems and transmission and distribution networks to the detriment of distributed generation. These constraints tend to reinforce the existing system and encourage network operators to limit as far as possible the number of distributed generation connections on their networks (Connor et al., 2002).

\section{Technical conditions for connection}

The technical standards imposed by network operators to ensure technical compatibility between network operation and distributed generation units, justified in the case of industrial facilities that might have an impact on the upstream part of the network, often act as disincentives for small-capacity installations. They lead to significant additional costs for such installations, sometimes calling into question the economic balance of a project.

This question of technical standards is just one facet of the numerous problems arising when distributed generation units are connected to the grid. In particular, problems arise regarding the question of connection voltage, the capacity of the network to transport the electricity and possible reinforcements to be envisaged, line protection technologies, the possibility of remote control by the network operator, and so on. (Decent, 2002).

Several countries seem to be solving this technical constraint concerning the connection of distributed generation to the grid by harmonising technical standards and connection procedures with a view to achieving greater transparency and limiting the possibilities for network operators to oppose the connection of distributed generation.

\section{Connection costs (deep / shallow costs)}

Connection of a distributed generation unit may in certain conditions have repercussions on the upstream part of the network (risks of overvoltage, for example).
The grid has therefore to be reinforced by modifying existing structures either to the immediate vicinity of the newly installed generating unit or on the network upstream. While it might seem logical to charge the direct costs of grid connection to the new generator, the question might be more difficult to resolve when it comes to the cost of reinforcing other parts of the network.

There are two different systems in use for charging for grid access, each with its own quite different consequences for distributed generators: in the case of socalled "deep costs", the generator pays all the costs involved in connecting the unit to the grid, including any upgrading of other parts of the grid, while in the case of "shallow costs", the generator only pays for connection to the required voltage level, with reinforcement costs being shared among all system users.

The deep costs option would seem to be a simple solution since it is merely a question of calculating all the additional costs to the network of connecting a new generator and having the generator pay these costs. But advance payment of these costs in full may act as a considerable barrier when connection charges are high (see Ofgem, 2002)

Moreover, this approach is not without problems because of its lack of transparency. Negotiation on an individual basis of the cost of reinforcement caused by a network connection is characterised by asymmetry of information between the generator and the network operator. It is therefore difficult for the regulatory authority itself to estimate how much of the reinforcement work is necessitated by the arrival of a new generator and how much corresponds to general upgrading of the network, which is the responsibility of the network operator.

\section{Use-of-system charges}

The question of use-of-system charges is complementary to that of connection charges. When generators do not pay all of the costs falling to the network for their connection, as in the case of a shallow costs policy, these costs must be recovered from all network users through system-use charges which cover several types of costs: grid reinforcement cost, operating and maintenance costs, capital depreciation costs, and electricity losses. If, in some conditions, distributed generation can help minimise line losses and network congestion and defer certain reinforcement investments, charges for using the network should ideally reflect this positive impact by differentiating distributed or local generation from conventional generation.

For transmission networks in Europe, the use of postage-stamp charges does not make it easy to recognise the benefits of local generation. Associated with the principle of shallow costs, the postage-stamp charge is independent of distance and designed to encourage new entrants into the electricity generation market. It does not place value on the positive effects of generating power close to the point of consumption in areas where there are shortages (nor does it dissuade generation in areas that already have surplus capacity), since it does not take into account the transmission 
ENER Forum 5. Technological change, market reform and climate policies.

Bucharest, Romania, 16-17 October 2003 - Presented papers DRAFT 19-10-03

costs and losses that are avoided when the electricity does not have to travel over long distances. As such it does not provide any locational signal or comparative advantage to generating units supplying local loads. With a standardised postage stamp system, distributed generation which essentially goes to local load in fact does not benefit from any advantages over conventional generation as far as the cost of using transmission and distribution networks is concerned.

Incentives for network operators to integrate distributed generation

A first important question is whether distributed generation will really have a positive impact on networks. For the producers, distributed generation may contribute to reducing line losses, situations in which congestion occurs and a corresponding need for network reinforcement because power generation and consumption would be closer. Furthermore, distributed generation can be used to support the network (voltage profile, current in network branches), provide ancillary services or more generally contribute to the overall stability of the system (IEA, 2002). But, to achieve that end distributed generation systems must be carefully located and operated to have a positive impact on the network. Locating distributed generation units on branches not subject to any particular constraint would have no effect on investments to reinforce the network. Above all distribution generation units must be available at times of peak network demand in order to restrict congestion.

Assuming distributed generation may have potential benefits on networks, there are two types of difficulty preventing network operators from taking them into account: first, the instruments that would allow them to identify precisely the positive impacts on network configurations that are necessarily specific are not currently available (Ofgem, 2002); second, the tariff framework that generally applies to network operators offers no incentive to take an interest in this type of option. In addition, it is very foreign to their essentially technical background.

\section{Conditions for access to the electricity market}

To boost competition in power generation, liberalisation needs, in theory, to create conditions for access to the electricity market that are equivalent for all generators. This of course concerns the means by which they are connected to the network but also the conditions in which new generators gain access to the various electricity markets to dispose of their output. In this respect distributed generation falls into two, quite separate categories: renewable energy sources or cogeneration which in many countries benefit of purchase obligations and the other technologies which do not enjoy the same advantages and must therefore conclude bi-lateral contracts or sell production on spot markets.

In the first case, market access is not a problem because output is sold to network operators or suppliers at a controlled price (fixed feed-in tariffs ) or on a contractual basis (competitive bidding). However, such provisions to support renewable energy or cogenera- tion may be called into question and replaced by mechanisms such as green certificates which integrate renewable energy production in the electricity market. In this case they would no longer benefit from purchase obligations.

Generators who do not have the benefit of purchase obligations must sell their electricity at the terms decided by the market. However, the rules governing the operation of electricity markets are largely unfavourable to small and intermittent producers:

- the cost of the transactions inherent in participation in electricity markets are substantial for limited output or require skills that occasional producers have difficulty acquiring;

- the setting up of balancing markets (see the experience gained with NETA in the UK) inflicts penalties on intermittent producers that exceed the cost of intermittent generation for the electrical system (Milborrow, 2001) and penalises generation that is not covered by a guarantee.

In conclusion, the existing obstacles to an extension of distributed generation are largely due to the absence of incentives for network operators to diversify their development strategies by making greater use of distributed generation. The existing incentives encourage the continuation of earlier technical schemes and do not allow the full benefit of any positive impacts of distributed generation to be reaped. Under these conditions it is generally in the interests of operators to discourage distributed generators from connecting to the grid. To avoid unfair treatment of generators, the first essential step is to introduce technical standards and across-the-board connection procedures for access to the grid which take account of the specificity of distributed generation technologies. At the same, the conditions of access to the electricity market for distributed generation must be examined, in particular with a view to changing the incentive schemes based on purchase obligations. Lastly, but with a time-frame that is perhaps longer due to the changes in practice involved, tariff mechanisms need to be adapted to maintain incentives for localisation, without necessarily creating further barriers for newcomers. Tariff mechanisms should try to take account of the positive impacts of distributed generation by sharing gains fairly between generators and distributors (ten Donkelaar, 2003).

\section{Institutional frameworks and the development of DG: case studies}

Three different institutional frameworks are presented thereafter ${ }^{1}$. They offer contrasted conditions for the deployment and integration of distributed generation in the electricity sector. Germany appears as the most favourable framework namely because of the

1 For a detailed presentation of national situations see for example, Mitchell \& Connor, 2002, Rapport Champsaur, 2000 and Leprich \& Bauknecht, 2003. 
ENER Forum 5. Technological change, market reform and climate policies. Bucharest, Romania, 16-17 October 2003 - Presented papers DRAFT 19-10-03

purchase obligation and guaranteed prices for renewable technologies. But the comparison with France which has also recently adopted a similar policy in favour of renewable technologies (feed-in tariffs) clearly shows that complementary factors such as grid and electricity market access are essential for the diffusion of distributed generation.

\section{Germany : a global incentive framework favourable to $D G$}

Regarding access to the grid, operators must connect generators who apply for access, the shallow costs principle applying to the breakdown of costs between generators and distributors. The cost breakdown favours distributed generators but is hindered, in Germany as in France, by the lack of a clear definition of which costs are covered by connection, paid by the generator, and which are covered by grid reinforcement, paid by the network operator. In addition, the loophole that enables network operators to refuse connections involving "excessive costs" adds to the confusion and causes numerous disputes.

In Germany distributed generation using renewable energy sources and some cogeneration units benefit from a purchase obligation associated with advantageous guaranteed prices. The question of use-of-system costs consequently does not arise for these generators. The balancing market has also a major advantage over other equivalent markets (NETA for example) because it enables generators to constitute groups, thus limiting the risks involved in individual imbalances. This feature limits the penalties inflicted on generators not guaranteeing their power output. In addition the generators with the largest risk of imbalance (wind farms and small-scale cogeneration) are not subject to the rule of passing through balancing markets, network operators being held responsible for maintaining a balance.

The law also stipulates that distributed generators must be compensated for network investment costs avoided by local production. In some cases this may represent a substantial source of additional income. However the difficulties involved in estimating exactly how much distributed generation contributes under peak load conditions and the inaccuracy of the available calculation procedures give rise to disputes with the network operators. Renewable energy sources that qualify for purchase obligations are not covered by this system.

Germany's institutional framework provides favourable conditions for the development of distributed generation. This framework is based on conditions for network access and the sale of electricity that are particularly advantageous for certain technologies (renewable energy sources and small-scale cogeneration) and adequate incentives for generators that do not penalise network operators. There are nevertheless still some difficulties, notably incomplete unbundling which may make some distributors or suppliers discourage consumers from producing their own electricity. The system also lacks a powerful regulatory body capable of establishing rules and preventing conflict between players.

United Kingdom : a centralised system which is changing to accept a greater share of $D G$

In accordance with the ambitious objectives regarding renewables and small cogeneration, the UK government has changed the existing incentives (former NFFO program) and set up working groups ${ }^{2}$ to identify the main hindrances and make proposals to stimulate the growth of distributed generation. The working groups concluded that, as things stand, there is no incentive for network operators to facilitate the connection of distributed generation. Indeed it may even be contrary to their interests, reducing their income.

The conditions for connection of distributed generation are much less favourable than in Germany. Generators are subjected to a deep-cost type tariff system which may be in some cases sufficiently high to discourage a large number of projects.

There is no tariff incentive for network operators to integrate distributed generators in their network as the resource asset base does not take into account connection and reinforcement costs. In some cases distributed generation may even result in a loss of income for distributors without a substantial reduction in power at peak periods. For network operators, distributed generation currently represents an additional expense, and something that they do not see as part of their core trade, namely distributing electricity to consumers.

With the reform of the electricity market (setting up the New Electricity Trading Arrangement) and the launch of a new incentive scheme (the Renewable Obligation), the conditions for access to the electricity market for generators using renewable energy sources have changed. Unlike the mechanism in Germany, UK producers are individually penalised for the imbalance they may cause, whether they in fact contribute to accentuating or, on the contrary, reducing imbalance in the system as a whole. This approach to dealing with differences is designed to encourage production according to a strict schedule but penalises wind farms and climatic cogeneration in particular.

In conclusion, the existing institutional framework in the UK seems much less favourable to the integration of distributed generation than in Germany. The network connection costs (deep costs) and the conditions for the resale of the electricity produced does not encourage intermittent or small generators, even if generators using renewable energy sources have the benefit of supplementary income from the sale of certificates (Renewable Obligation). The government has nevertheless set up working groups to identify hindrances and make proposals to encourage distributed generation which suggests that a political determination exists.

\footnotetext{
2 The Embedded Generation Working Group and the Distributed Generation Coordinating Group which has succeeded to the EGWG.
} 
ENER Forum 5. Technological change, market reform and climate policies. Bucharest, Romania, 16-17 October 2003 - Presented papers DRAFT 19-10-03

France : the difficulty of integrating $D G$ in historically centralised system

Compared with the two countries discussed above, the institutional framework in France seems less favourable to distributed generation of electricity. While the fixed tariffs introduced in 2001 are relatively close to the ones in Germany, the structure of the electricity network and the technically oriented culture inherited from the established operator do little to encourage the development of decentralised solutions.

In the same way as most of the electrical networks in European countries - except those with a strong tradition of decentralisation - the French network is ill prepared to receive a massive injection of distributed generation. The issue of sharing reinforcement costs between players is therefore particularly sensitive in France. Initially ${ }^{3}$, consumers paid all use-of-system costs (transmission and distribution). There was no specific tariff system for connections or the possible need for reinforcement, negotiated on an individual basis. The lack of an explicit framework for connection costs made it necessary to resort to ad hoc procedures that inevitably had a negative impact on the transparency of connection procedures for independent generators. It also fuelled accusations against EDF of discouraging new generators (Champsaur, 2000). The government decree on the Transport and Distribution use-of-system clarified this point by creating set procedures for the connection of new generators and new tariff systems under which any network reinforcement costs must be paid by the relevant network operators (shallow costs).

Both the technically-oriented background of the network operators and operating rules inherited in part from EDF contribute to a cautious approach to integrating distributed generation. Operators acknowledge that building distributed generation units may help to solve some congestion problems, reduce line losses, maintain voltage quality, etc. But they also set very specific conditions: such units must be distributed all over the network and offer a good level of availability with a low risk of failure. They add that the present situation does not correspond to this ideal configuration and consequently distributed generation cannot hope to deliver the benefits it claims, particularly if connection requests mainly concern wind farms located in areas of low consumption with a risk of nonavailability.

French policy on support for distributed generation centres mainly on introducing purchase obligations and guaranteed prices for electricity from renewable energy sources and cogeneration. The broader question of how to integrate distributed generation in the electrical system as a whole has not been addressed. There are no additional incentive schemes that take into account the potentially positive impact of local production. This is likely to hinder the growth of a dynamic in favour of distributed generation technologies which do not bene-

\footnotetext{
3 Before the introduction of a provisional tariff system in 1999.
}

fit from purchase obligations and guaranteed prices, and are currently held back by uncertain profitability.

\section{Conclusion}

A number of factors conducive to the emergence of distributed electricity generation systems can be identified. They include the improved performance of smallscale technologies along with a distinct decline in the scale effects enjoyed by conventional electricity generating technologies, a selection environment that has become more risky and less favourable to capitalintensive investments, and the growing difficulties in extending or reinforcing networks. These processes are reinforced by the liberalisation of the electricity sector which facilitates the entry of new players by simplifying grid access procedures, stimulates competition and differentiation of products and services offered to consumers and, thanks to greater transparency of prices, creates niches in which distributed generation can develop.

The situation does, however, vary considerably among the Member States depending on the extent to which the electricity sector is centralised. Thus, in the Netherlands, Denmark and Germany, distributed generation methods benefit from favourable development conditions (grid access, resale of the electricity) but they also seem to be better integrated in the electricity system. In the United Kingdom, distributed generation plays only a minor role and development conditions are far less advantageous. But a serious political commitment to reform the system in depth could create much more propitious conditions. In the case of France, the structure of the network, the technical culture of the established operator and the speed at which liberalisation is taking place have so far not led to a serious examination of the opportunities opened up by distributed generation. If things are to change, the connection of distributed electricity generation to the network must not be perceived simply as a constraint but also in terms of their potential positive impacts. So far, this point of view is not shared by all the players in the electricity system.

\section{References}

Connor, P., Mitchell, C., 2002, A review of four European regulatory systems and their impact on the deployment of distributed generation, Report for the Sustelnet project, The University of Warwick.

Ofgem, 2002, Distributed generation: price controls, incentives and connection charging - Further discussion, recommendations and future action, March 2002.

Decent, 2002, Decentralised generation: development of EU policy, Report in the framework of the DECENT project.

IEA, 2002, Distributed Generation in liberalised electricity markets, International Energy Agency, Paris 2002. 
ENER Forum 5. Technological change, market reform and climate policies.

Bucharest, Romania, 16-17 October 2003 - Presented papers DRAFT 19-10-03

Leprich U., Bauknecht D., 2003, Review of current electricity policy and regulation, German Study Case, Sustelnet project, Oko Institut, Izes.

Markard J., Truffer B., 2003, "The impacts of market liberalization on innovation processes in the electricity sector", in this issue.

Milborrow, D., 2001, Penalties for intermittent sources of energy, Working Paper for the PIU Energy Review, http://www.cabinet-office.gov.uk/innovation/

2002/energy/workingpapers.shtml

Mitchell C., Connor P., 2002, Review of current electricity policy and regulation, UK Study Case, Sustelnet project, the University of Warwick.

Rapport Champsaur, 2000, Rapport du Groupe d'expertise économique sur la tarification des réseaux de transport et de distribution de l'électricité, janvier 2000,http://www.industrie.gouv.fr/energie/electric/pdf/ $\underline{\text { tar ele2.pdf }}$

Ten Donkelar M., 2003, "Solutions and options for the integration of distributed generation into electricity supply systems", in this issue. 